\title{
Modifiable Risk Factor of Coronary Heart Disease Incident on Patients with Diabetes Mellitus Type 2
}

\author{
Masrizal Dt Mangguang1, Sri Hardian² \\ ${ }^{1}$ Public Health Faculty, Andalas University, Padang, West Sumatra 25148, Indonesia \\ ${ }^{2}$ Epidemiology and Biostatistic, Public Health Faculty, Andalas University, Padang, West Sumatera 25148, Indonesia
}

\begin{abstract}
Article Info
Article history:

Received Jun 9, 2016

Revised Aug 15, 2016

Accepted Aug 20, 2016

Keyword:

CHD

Diabetes mellitus type 2

Hypertension

Obesity

Smooking

ABSTRACT

The aim of this research is to determine the risk factors related to coronary heart disease incidence in type 2 diabetes mellitus patient at Dr. M. Djamil Padang Hospital. This was an analytic research with case control study design around October 2014 until May 2015. Samples consisted of 39 cases and 39 controls with matching age and sex. The data were analyzed by using univariate, bivariate by using McNemar test, multivariate by using regression logistic test and stratification. The result showed that hypertension $\mathrm{p}=0.002$ $(\mathrm{OR}=5,95 \% \mathrm{CI} 1.09-22.82)$, obesity $\mathrm{p}=0.0001(\mathrm{OR}=6,95 \% \mathrm{CI} 2.08-17.29)$, duration of $\mathrm{DM} p=0.01(\mathrm{OR}=3.2,95 \%$ CI 1.17-8.73) and smooking $\mathrm{p}=$ $0.002(\mathrm{OR}=7,95 \% \mathrm{CI} 1.59-30.80)$ were associated with coronary heart disease incidence in type $2 \mathrm{DM}$ patient. The most dominant risk factor that was associated with coronary heart disease incidence in type $2 \mathrm{DM}$ patient at Dr. M. Djamil Hospital was obesity $\mathrm{p}=0.0001$ ( $\mathrm{OR}=10.2$, 95\% CI 3.0833.81). Hypertension $\mathrm{OR}=11.25$, duration of $\mathrm{DM} \mathrm{OR}=18$, smooking $\mathrm{OR}=16.2$, sport activity $\mathrm{OR}=18.6$ and income level $\mathrm{OR}=15.7$ had interaction of the association between obesity and coronary heart disease incidence in type 2 DM patient. Hypertension, obesity, duration of DM and smooking were risk factors that associated to coronary heart disease incidence in type 2 DM patient. Then, the most dominant risk factor that associated to coronary heart disease incidence in type 2 DM patient at Dr. M. Djamil Padang was obesity. Hypertension, duration of DM, smooking, sporct activity and income level had interaction of the association between obesity and coronary heart disease incidence in type $2 \mathrm{DM}$ patient.
\end{abstract}

Copyright $@ 2016$ Institute of Advanced Engineering and Science. All rights reserved.

\section{Corresponding Author:}

Masrizal Dt Mangguang,

Public Health Faculty,

Andalas University,

Padang, West Sumatra 25148.

Email: masrizal.dtmangguang@gmail.com

\section{INTRODUCTION}

Diabetes mellitus (DM) is one of the major causes of health problems. DM is a chronic disease that characterized by increased levels of sugar in body because pancreas unable to produce insulin as needed. About $90 \%$ patient Diabetes Mellitus was dominated by Diabetes Mellitus type 2. .DM type 2 caused by peripheral insulin resistance that increased basal insulin secretion and finally made pancreas exhauted. DM type 2 is common in adults and the elderly [1].

According to IDF Diabetes ATLAS (2013), there were 382 million people in the world living with diabetes mellitus. DM patients in the world are in the age range 40-59 years of which $80 \%$ in the country with middle income per capita. Indonesia was ranked seventh with 8.5 million people living with diabetes in 2013 and estimated increase in 2035 which 14.1 million people becoming diabetes. According to 
RISKESDAS (2007) Indonesia prevalence of diabetes was 5.7\%. The prevalence of diabetes by province shows West Sumatra has a quite high prevalence 4.1\% [2]-[4].

The unproperly managed DM type 2 can cause a chronic disease and causes eyes, feet, kidneys and vascular complications. Vascular complications consisted of macrovascular complications (coronary heart disease, stroke and peripheral vascular disease) and microvascular (retinopathy, nephropathy, and neuropathy). About $65 \%$ of patients with diabetes die from coronary heart disease. The Frammingham Study showed that patient with DM Tipe 2 increases the risk developed CHD, it 2 times greater in men and 3 times greater in women which improve mortality and morbidity of CHD in patient with DM Tipe 2 [1],[5],[6].

World Health OrganizationGlobal Status Report (2010) shows the proportion cause of death in noncommunicable diseases at the age $\leq 70$ years contained in cardiovascular disease that first ranked by $39 \%$ in the world. This is followed by non-communicabel disease, diabetes, cancer, respiratory kronic and others [7]. Results SKRT (2001) shown many of the deaths in Indonesia's population are caused by heart disease and blood vessels in the amount of $26.3 \%$. National RISKESDAS report (2007) shows that the prevalence of heart disease in Indonesia amounted to $7.2 \%$. The prevalence of heart disease in the province of NAD $12.6 \%$ sequentially, $11.8 \%$ of Central Sulawesi and West Sumatra 11.3\%. West Sumatra including three large provinces in the prevalence of CHD in Indonesia [2],[8].

West Sumatra RISKESDAS Report (2007) showed the highest prevalence of heart disease in the District/ Rhe South Coast by $25 \%$ and the lowest in the Padang city, by $2.5 \%$. Prevalence in Padang City was low but has significant meaning to the increase in cardiac cases annually. According to the Health Department of Padang city in 2011, CHD was included on 10 diseases leading cause of death in Padang. This proofing by The Padang City Health Department Profile that there was increased the number of deaths caused by heart disease in 2011-2013. In 2011 there were cases of heart disease deaths by 82 cases with the proportion of $20.7 \%$. In 2012 there was an increase of cases of heart disease mortality by 89 cases with the proportion of $19 \%$. Furthermore, in 2013 an increase in heart disease deaths by 99 cases with the proportion of $16.9 \%$ [3],[9]-[11].

The percentage of mortality as well asmorbidity from CHD can be increased in patients with diabetes mellitus type 2 . This is because patients with diabetes type 2 have 2 times risk greater for CHD. Risk factor of CHD was consisted of a non factor modification and modification factor. Non modification factors include age, gender and heredity history of CHD. Factors modification consists of physiological factors (long suffering from diabetes, obesity hipertensidan), behavioral factors (smooking, alcohol consumption, physical activity and sleep patterns/stay up) and socio-economic factors (income and education level).

Several studies related to CHD risk factors in patients with diabetes type 2 among the study Fadma et al (2013) shows the gender factor, dyslipidemia, smooking, duration of diabetes, hypertension and obesity are the risk factors for CHD events. Saowapa Reasearch (2006) showed that a non modification factors (age and history of descent), modification factors (hypertention, cholesterol, diabetes mellitus, obesity, menopause, smooking, physical activity, alcohol consumption, stress, depression) and factors contextual (level of education, level of income, sidtance, transportation, adn poverty) is a cardiovascular risk factor including CHD [1],[12].

Initial studies through medical records at Dr Dr.M.Djamil which is the main referral hospital in West Sumatra is known that, increased occured cases of CHD in patients with diabetes mellitus type 2 in 2010-2013. In 2010, there were 13 cases of CHD from 183 patients with diabetes type 2 (7\%). In 2011 there was an increase of 15 cases from 183 cases of CHD patients with DM type 2 (28\%). In 2012, there were decreased by 13 cases of CHD cases from 198 patients with diabetes type 2 (6\%). Furthermore, in 2013 there was an increase of cases is quite high at 74758 cases of CHD patients with type 2 diabetes mellitus $(9.76 \%)$ [13]. From the above description problems, researchers interested to research more about modifiable risk factor for coronary heart disease (CHD) in patinet with diabetes type 2 in Dr. M. Djamil Padang Hospital in 2014.

\section{RESEARCH METHOD}

This research is a quantitative study with case control study design. This study used sample from the case group and the control group and then compare the distribution of modifiable risk factors for coronary heart disease incident in patinet with diabetes mellitus type 2 in both groups. The study was conducted at Dr. M. Djamil Padang Hospital from October 2014 until May 2015.

The cases population in this study were all patients DM type 2 who are diagnosed with CHD by doctors and recorded in the medical records of Dr.M.Djamil Padang Hospital in 2014 who lived in Padang. And the control population are all patient DM Tipe 2 who were not diagnosed with CHD by doctors and recorded in the medical record of Dr. M. Djamil Padang Hospital in 2014. 
Sample size in this study based on a case-control sample size formula pairs as samples obtained minimum ampunt of 35 people. Then, samples added with 10\% drop out therefore total sample is 78 sample consisted of 39 cases and 39 controls. The case sample in this study were taken by using simple random sampling method. The control is obtained by using purposive sampling method and matched by age and gender.

\section{RESULTS AND ANALYSIS}

Table 1 is the univariate analysis result, it showed respondents who had hypertension in the case group amounts of 26 people (33.33\%) much more if compared to the control group (23.08\%).For obesityshowed that respondents who experienced of obesity is more occurred in the case group amounts of 26 people $(33.33 \%)$ compared to the control group amounts of 6 people $(7.69 \%)$. For long suffering of diabetes found that respondents with DM at large form 10 years is more in the case group amounts of 21 people $(26.92 \%)$ compared withthe control group amounts of 10 people (12.82\%).For smooking habitsfound that respondents who have much more smooking habits was in the case group amounts of 26 people $(33.33 \%)$ comparedwiththe control group amounts of 14 people $(17.95 \%)$. For sportsfound that respondents who do not exercise was much more in control group amounts of 31 people $(39.74 \%)$ compared to the cases amounts of 27 people (34.62\%).For income level, it can be seen that respondents who have less income levels than the minimum wage more was much in the control group amounts of 23 people (29.49\%) comparedwiththe cases amounts of 20 people $(25.64 \%)$

Tabel 1. Distibution Frequency of Independent And Dependent Variables

\begin{tabular}{|c|c|c|c|c|c|c|c|}
\hline \multirow{2}{*}{ No. } & \multirow{2}{*}{ Variabel } & \multicolumn{2}{|c|}{ Cases } & \multicolumn{2}{|c|}{ Control } & \multicolumn{2}{|c|}{ Total } \\
\hline & & $\mathrm{f}$ & $\%$ & $f$ & $\%$ & $\mathrm{f}$ & $\%$ \\
\hline \multirow[t]{4}{*}{1} & Hipertension & & & & & & \\
\hline & Yes & 26 & 33.33 & 18 & 23.08 & 44 & 56.41 \\
\hline & Not & 13 & 16.67 & 21 & 26.92 & 34 & 43.59 \\
\hline & Total & 39 & 50 & 39 & 50 & 78 & 100 \\
\hline \multirow[t]{4}{*}{2} & IMT & & & & & & \\
\hline & Obesitas & 26 & 33.33 & 6 & 7.69 & 32 & 41.02 \\
\hline & Not Obesitas & 13 & 16.67 & 33 & 42.31 & 46 & 58.98 \\
\hline & Total & 39 & 50 & 39 & 50 & 78 & 100 \\
\hline \multirow[t]{4}{*}{3} & Long Suffering DM & & & & & & \\
\hline & $\geq 10$ years & 21 & 26.92 & 10 & 12.82 & 31 & 39.74 \\
\hline & $<10$ years & 18 & 23.08 & 29 & 37.18 & 47 & 60.26 \\
\hline & Total & 39 & 50 & 39 & 50 & 78 & 100 \\
\hline \multirow[t]{4}{*}{4} & Smoke & & & & & & \\
\hline & Yes & 26 & 33.33 & 14 & 17.95 & 40 & 51.28 \\
\hline & Not & 13 & 16.67 & 25 & 32.05 & 38 & 48.72 \\
\hline & Total & 39 & 50 & 39 & 50 & 78 & 100 \\
\hline \multirow[t]{4}{*}{5} & Sport & & & & & & \\
\hline & Not & 27 & 34.62 & 31 & 39.74 & 58 & 74.36 \\
\hline & Yes & 12 & 15.38 & 8 & 10.26 & 20 & 25.64 \\
\hline & Total & 39 & 50 & 39 & 50 & 78 & 100 \\
\hline \multirow[t]{4}{*}{6} & Income Level & & & & & & \\
\hline & $<\mathrm{UMR}$ & 20 & 25.64 & 23 & 29.49 & 43 & 55.13 \\
\hline & $\geq \mathrm{UMR}$ & 19 & 24.36 & 16 & 20.51 & 35 & 44.87 \\
\hline & Total & 39 & 50 & 39 & 50 & 78 & 100 \\
\hline
\end{tabular}

Table 2 is the bivariate analysis resultit is known that hypertension has a value of $\mathrm{p}=0.02$ and obesity has a value of $p=0.0001$. Then, smooking has a value of $p=0.002$ and the long suffering from diabetes has a value of $\mathrm{p}=0.01$. Furthermore based on table 3 a domant risk factor affecting the incidence of CHD in Dr. M. DjamilPadang Hospital at 2014 were obesity with p=0.0001 and OR 10.2 (95\% CI 3.08 to 33.81).

Tabel 2. Association between Independen and Dependen Variables

\begin{tabular}{|c|c|c|c|c|c|c|c|c|c|}
\hline \multirow{2}{*}{ No. } & \multirow{2}{*}{ Variabel } & \multicolumn{2}{|c|}{ Kasus } & \multicolumn{2}{|c|}{ Kontrol } & \multicolumn{2}{|c|}{ Total } & \multirow{2}{*}{$\begin{array}{c}\text { OR } \\
(95 \% \mathrm{CI})\end{array}$} & \multirow{2}{*}{$p$ value } \\
\hline & & $\mathrm{f}$ & $\%$ & $\mathrm{f}$ & $\%$ & $\mathrm{f}$ & $\%$ & & \\
\hline \multirow[t]{4}{*}{1} & Hipertension & & & & & & & \multirow{4}{*}{$\begin{array}{c}5 \\
(1.09-22.82)\end{array}$} & \multirow{4}{*}{0.02} \\
\hline & Yes & 16 & 41.03 & 10 & 25.64 & 26 & 66.67 & & \\
\hline & Not & 2 & 5.13 & 11 & 28.20 & 13 & 33.33 & & \\
\hline & Total & 18 & 46.16 & 21 & 53.84 & 39 & 100 & & \\
\hline \multirow[t]{2}{*}{2} & IMT & & & & & & & & \\
\hline & Obesitas & 2 & 5.13 & 24 & 61.54 & 26 & 66.67 & 6 & 0.0001 \\
\hline
\end{tabular}

Modifiable Risk Factor of Coronary Heart Disease Incident on Patients with .... (Masrizal Dt Mangguang) 


\begin{tabular}{|c|c|c|c|c|c|c|c|c|c|}
\hline & Not Obesitas & 4 & 10.26 & 9 & 23.07 & 13 & 33.33 & \multicolumn{2}{|l|}{$(2.08-17.29)$} \\
\hline & Total & 6 & 15.39 & 33 & 84.61 & 39 & 100 & & \\
\hline \multirow[t]{4}{*}{3} & Long Suffering DM & & & & & & & \multirow{4}{*}{$\begin{array}{c}3.2 \\
(1.17-8.73)\end{array}$} & \multirow{4}{*}{0.01} \\
\hline & $\geq 10$ years & 5 & 12,82 & 16 & 41,03 & 21 & 53,85 & & \\
\hline & $<10$ years & 5 & 12.82 & 13 & 33.33 & 18 & 46.15 & & \\
\hline & Total & 10 & 25.64 & 29 & 74.36 & 39 & 100 & & \\
\hline \multirow[t]{4}{*}{4} & Smoke & & & & & & & & \\
\hline & Yes & 12 & 30.77 & 14 & 35.90 & 26 & 66.67 & \multirow{3}{*}{$\begin{array}{c}7 \\
(1.59-30.80)\end{array}$} & \multirow{3}{*}{0.002} \\
\hline & No & 2 & 5.13 & 11 & 28.20 & 13 & 33.33 & & \\
\hline & Total & 14 & 35.90 & 25 & 64.10 & 39 & 100 & & \\
\hline \multirow[t]{4}{*}{5} & Sport & & & & & & & \multirow{4}{*}{$\begin{array}{c}0.6 \\
(0.21-1.65)\end{array}$} & \multirow{4}{*}{0.33} \\
\hline & Not & 21 & 53.85 & 6 & 15.38 & 27 & 69.23 & & \\
\hline & Yes & 10 & 25,64 & 2 & 5,13 & 12 & 30,77 & & \\
\hline & Total & 31 & 79.49 & 8 & 20.51 & 39 & 100 & & \\
\hline \multirow[t]{4}{*}{6} & Income Level & & & & & & & \multirow{4}{*}{$\begin{array}{c}0.75 \\
(0.31-1.78)\end{array}$} & \\
\hline & < UMR & 11 & 28.20 & 9 & 23.08 & 20 & 51.28 & & \multirow{3}{*}{0.51} \\
\hline & $\geq \mathrm{UMR}$ & 12 & 30.77 & 7 & 17.95 & 19 & 48.72 & & \\
\hline & Total & 33 & 58.97 & 16 & 41.03 & 39 & 100 & & \\
\hline
\end{tabular}

The dominant risk factor is obesity. Furthermore conducted stratified analyzes was used to see the interaction or effect modifier or an increased risk of obesity relationship with CHD incident on patients with diabetes type 2 based on the status of hypertension, long suffering from diabetes, smooking, exercise and income level.

Tabel 3. Multivariat Analysis (Dominant Variables)

\begin{tabular}{cccccc}
\hline Variabel & OR & $95 \%$ CI & Coefficient & SE & $p$ value \\
\hline Long Suffering DM & 3.6 & $1.12-11.97$ & 1.2986 & 0.6044 & $0.03^{*}$ \\
Hipertension & 1.9 & $0.61-5.93$ & 0.6460 & 0.5794 & 0.26 \\
Smoke & 2.4 & $0.80-7.61$ & 0.9088 & 0.5718 & 0.11 \\
Obesity & 10.2 & $3.08-33.81$ & 2.3233 & 0.6110 & $0.0001^{*}$ \\
\hline
\end{tabular}

Based on Table 4 the result stratified analysis showed that respondent patients with diabetes type 2 who are obese based on the status of hypertension $(\mathrm{OR}=11.2)$, long suffering from diabetes $\geq 10$ years $(\mathrm{OR}=18)$, smooking $(\mathrm{OR}=16.2)$, sports $(\mathrm{OR}=18.6)$ and low income $(\mathrm{OR}=15.7)$.

Tabel 4. Analisis Stratification Obesity Relationships with Coronary Heart Disease in Patients with Type 2 diabetes based on the Status of Independent Variables

\begin{tabular}{ccc}
\hline Status (Variabel) & OR $(95 \% \mathrm{CI})$ & $p$ value \\
\hline Hipertension & $11.2(2.52-50.08)$ & 0.001 \\
Non Hipertension & $9.6(1.83-50.28)$ & 0.012 \\
Long Suffering DM $\geq 10$ years & $18(1.88-171.88)$ & 0.01 \\
Long Suffering DM $<10$ years & $9.6(2.42-37.94)$ & 0.001 \\
Smoke & $16.2(2.88-91.83)$ & 0.001 \\
Non Smoke & $6.1(1.33-28.20)$ & 0.03 \\
Not Sport & $18.6(4.44-78.35)$ & 0.00002 \\
Sport & $3.3(0.51-21.58)$ & 0.40 \\
Income level $\geq$ UMR & $15.7(2.86-86.57)$ & 0.001 \\
Income level <UMR & $8.4(1.89-38.56)$ & 0.01 \\
\hline
\end{tabular}

The statistical test results obtained by using the McNemar test and find a significant relationship between hypertension, obesity, diabetes mellitus and long smooking variables with CHD incident on patients with diabetes type 2 in the Dr. M. Djamil Padang Hospital in 2014.

Hypertension is a condition when blood pressure under the normal limit of $140 / 90 \mathrm{mmHg}$. The unwell controlled hypertension causing damage to the muscles in the heart. If it occurs in patients with diabetes type 2 are become 2-3 times risk for CHD [14],[15].

Obesity can be measured by BMI. Obesity has a greater risk of developing CHD since obesity leads to atherosclerosis, hypertension, hyperlipidemia, and other conditions. People who are obese need to do physical activities such as exercise to control hypertension, hyperlipidemia, diabetes and maintain blood lipid profiles [16]-[19]. 
Long-suffering of diabetes that risk for CHD in patients with diabetes type 2 was in ranges $\geq 10$ years. The length of a person suffering from diabetes affected by controlling their sugar and irregular food. The length of a person suffering from diabetes have an increased risk of chronic complications, including coronary heart disease [20],[21].

Smooking is a habit by one or more cigarettes each day. Smooking habits cause clumping and calcification of blood vessel walls. Besides smooking increases cholesterol and free fatty acids which cause constriction of blood vessels in the heart [18],[22].

Sport is one of the physical activity. Ideally, sports activities should be done 3-5 times a week. Exercise is very beneficial for the control of cholesterol, HDL, triglycerides, expenditure energy and help the circulation of bloodfacilitate. This leads to be avoided the deposition of cholesterol in the blood vessels. This also reduce the risk of CHD, especially in patients with diabetes type 2 [23],[24].

Income level is one of the economic status measured. Income level can affect a person's health status. This is due to a range of access to health care and traffic purchasing power of a person for health [18],[24].

Multivariate analysis showed the most dominant factor for developing CHD in patients with diabetes mellitus type is obesity. It is caused by a person within obesity state may lead to increased levels of cholesterol, hypertension and diabetes. Furthermore, if patients with diabetes type 2 are obese and have a hypertension, long-suffering DM big at 10 years, smooking, not exercising and having a low income status will increase at greater risk for CHD than those who did not have one that status [14],[16],[18].

The increased risk ocorred CHD for patients with diabetes who are obese and have one of the 5 status variables. This is caused by the interaction between obesity and the 5 variables and causing chronic complications and improve greater risk for CHD. Between obesity and the five variables can affected the cholesterol, blood sugar, HDL, triglycerides, thrombus formation, atherosclerosis and so on blood flow state the blood vessels in the heart. It has a greater risk of CHD if there is an interaction of both. Therefore it is necessary for patients with diabetes type 2 who are obese in controlling blood pressure, blood sugar, stop smooking habits and exercise in order to reduce the risk for CHD.

\section{CONCLUSION}

Hypertension, obesity, duration of DM and smooking were risk factors associated to coronary heart disease incidence in type 2 DM patients. The most dominant risk factor was obesity. Hypertension, duration of DM, smooking, sporct activity and income level had interaction of the association between obesity and coronary heart disease incidence in those patient.

\section{ACKNOWLEDGEMENTS}

Thanks to the Dean of The Public Health Faculty Andalas University, and staffs of Dr. M. Djamil Padang Hospital who supported this study.

\section{REFERENCES}

[1] Yuliani F., Oenzil F., Iryani D., "Various Risk Factors Relations against Coronary Heart Disease Incident in Patients with Diabetes Mellitus Type 2," Health of Andalas, vol. 3, pp. 37-40, 2013.

[2] Ministry of Health, "Basic Health Research (RISKESDAS) 200720072008 National Report,"

[3] Department of Health, "Basic Health Research (RISKESDAS) 20072008 West Sumatra,"

[4] International Diabetic Federation, "IDF Diabetes ATLAS Sixth Edition," 2013.

[5] "Textbook of Medicine," Jakarta, Publishing Center Department of Medicine Faculty of Medicine, University of Indonesia, 2006

[6] Yanti, Hadisaputro S., Suhartono T., "Risk Factors of Coronary Heart Disease incidence in patients with Type 2 Diabetes Mellitus (Case Study at Dr Dr.Kariadi Semarang),"

[7] WHO, "World Health Statistic," 2014

[8] Ministry of Health, "Household Health Survey 2001," Jakarta, 2001.

[9] Padang Health Agency, "Padang Health Profile Year 2011 Edition 2012," in: Healthy BP, editor, Padang, 2012.

[10] Padang Health Agency, "Padang Health Profile Year 2012 Edition 2013," in: Healthy BP, editor, Padang, 2013.

[11] Padang Health Agency, "Padang Health Profile Year 2013 Edition 2014," in: Healthy BP, editor, Padang, 2014.

[12] Dedhkhard S., "Risk Factors of Cardiovascular Disease in Rural Thai Women," in: Arizona TUo, editor, 2006.

[13] Dr Dr. M.Djamil Padang, "Medical Record Data Years 2010-2013," Padang, Dr Dr.M.Djamil Padang, 2014.

[14] F. Yuliani, F. Oenzil, Iryani D., "Relationships Various Risk Factors against Coronary Heart Disease Events in Patients withDiabetes Mellitus Type 2," Jurnal Kesehatan Andalas, vol. 3, pp. 37-40, 2013.

[15] Yanti, S. Hadisaputro, Suhartono T., "Risk Factors of Coronary Heart Disease incidence in patients with Diabetes Mellitus Type 2, (Cases study in RSUP Dr.Kariadi Semarang)," 
[16] A. O. Odegaard, W. Puay, M. D. Gross, J. Min, Pereira M. A., "Combined Life Style Factors and Cardiovascular Disease Mortality in Chinese Men and Women," in: Minnesota UO, editor, 2011.

[17] Mc Gorrian, S. Yusuf, S. Islam, H. Jung, Rangarajan, A. Avezum, et al., "Combinating Modifiable Coronary Heart Disease in Multiple Regions of the World," European Heart Journal, vol. 32, pp. 581-90, 2010.

[18] S. K. Trisnawati, Setyonegoro S., "Risk Factors Genesis Deiabetes Mellitus Type 2 in Cengkareng, West Jakarta Health Center in 2012," Jurnal Ilmiah Kesehatan, vol. 5, 2013.

[19] Octari C., "Relationship Socio-Economic Status and Lifestyle with Genesis Obesity Students of SD Negeri 08 Alang Lawas Padang," Jurnal Kesehatan Andalas, vol. 3, 2014.

[20] Richard, Stevens, V. Khotari, Amanda, Adler, Irine, et al., "A Model For The Risk Of Coronary Heart Disease in Type II Diabetes," Clinical Science, vol. 101, 2001.

[21] R. C. Turner, H. Millnes, Neil S., Manley M., Holman, "Risk Factors For Coronary Heart Disease in Non-Insulin Dependent Diabetes Melitus," Journal BMJ, vol. 316, 1998.

[22] S. Bonakdaran, S. Ebrahimzadeh, Noghabi S. H., "Cardiovaskular Disease and Risk Factors in Patients with Type 2 Diabetes Mellitus in Masshad, Islamic Republic of Iran," Eastern Mediterranean Health Journal, vol. 17, 2011.

[23] S. A. Marliyati, M. Simanjuntak, Kencana D. S., "Socioeconomic and body mass index (BMI) Adult Male In Relation With Coronary Heart Disease Risk Factors in Rural and Urban Bogor, West Java," Jurnal Gizi dan Pangan, vol. 5, pp. 15-25, 2005.

[24] B. Hu F., "Dietary Fat Intake and The Risk of Coronary Heart Disease in Woman," Massachussets Medical Society, vol. 337, pp. 1491, 1997. 